\title{
Leishmania Interferes with Host Cell Signaling to Devise a Survival Strategy
}

\author{
Suvercha Bhardwaj, Neetu Srivastava, Raki Sudan, and Bhaskar Saha \\ Lab no. 5, National Center for Cell Science, University of Pune, Ganeshkhind, Pune 411 007, India \\ Correspondence should be addressed to Bhaskar Saha, sahab@nccs.res.in
}

Received 31 July 2009; Revised 21 October 2009; Accepted 28 January 2010

Academic Editor: Abhay R. Satoskar

Copyright () 2010 Suvercha Bhardwaj et al. This is an open access article distributed under the Creative Commons Attribution License, which permits unrestricted use, distribution, and reproduction in any medium, provided the original work is properly cited.

The protozoan parasite Leishmania spp. exists as extracellular promastigotes in its vector whereas it resides and replicates as amastigotes within the macrophages of its mammalian host. As a survival strategy, Leishmania modulates macrophage functions directly or indirectly. The direct interference includes prevention of oxidative burst and the effector functions that lead to its elimination. The indirect effects include the antigen presentation and modulation of $\mathrm{T}$ cell functions in such a way that the effector $\mathrm{T}$ cells help the parasite survive by macrophage deactivation. Most of these direct and indirect effects are regulated by host cell receptor signaling that occurs through cycles of phosphorylation and dephosphorylation in cascades of kinases and phosphatases. This review highlights how Leishmania selectively manipulates the different signaling pathways to ensure its survival.

\section{Introduction}

Leishmaniasis, caused by the protozoan parasite of the genus Leishmania, is an infection that occurs primarily in the tropical and subtropical regions of the world. Leishmania is a dimorphic protozoan parasite that resides as an extracellular flagellate-promastigotes - in its sand fly vector and as an intracellular aflagellate-amastigotes-in macrophages of its mammalian host [1]. Leishmaniasis is characterized by the parasite-induced immunosuppression executed not only by active subversion but also by immune deviation such that the resulting immune responses suppress the antileishmanial immune response further. Because macrophages are not only the host cells for the parasite but also sentinels of the immune system, these cells are targeted by the parasite for immune modulation to ensure their survival. The parasite interferes with the signaling system of the cell such that the effector functions triggered by various cell surface receptors are either actively suppressed or are altered to result in the immune responses that promote parasite survival. A variety of mechanisms potentially contributing to mononuclear phagocyte deactivation during intracellular infection have been identified [2]. Of considerable interest is the evidence that intracellular pathogens are able to impair cell signaling pathways required for host cell activation that may eventuate in their elimination $[2,3]$. Cell signaling is regulated by two principal classes of enzymes, protein kinases and phosphoprotein phosphatases [4, 5] (Figure 1).

As the signals are transduced in cascades of kinases and phosphatases through cycles of phosphorylation and dephosphorylation, the parasitic interference often targets these signaling intermediates [6]. Herein, we will analyze the alterations in the signaling of some receptors in Leishmaniainfected macrophages and will associate those alterations with the altered responsiveness of the macrophages to the ligands of those receptors.

\section{Leishmania Modulates the Receptor Responsiveness in Macrophages}

2.1. Regulation of CD40 Responsiveness and Mitogen Activated Protein Kinase Family. The interaction between CD40, a costimulatory molecule expressed on macrophages, B cells, and dendritic cells [7], and its ligand CD40 ligand (CD154) on T cells [8] results in Th subset skewing to Th1 type. Consistent with the proposition that Th1 cells are responsible for protection against Leishmania major infection, the CD40-deficient 


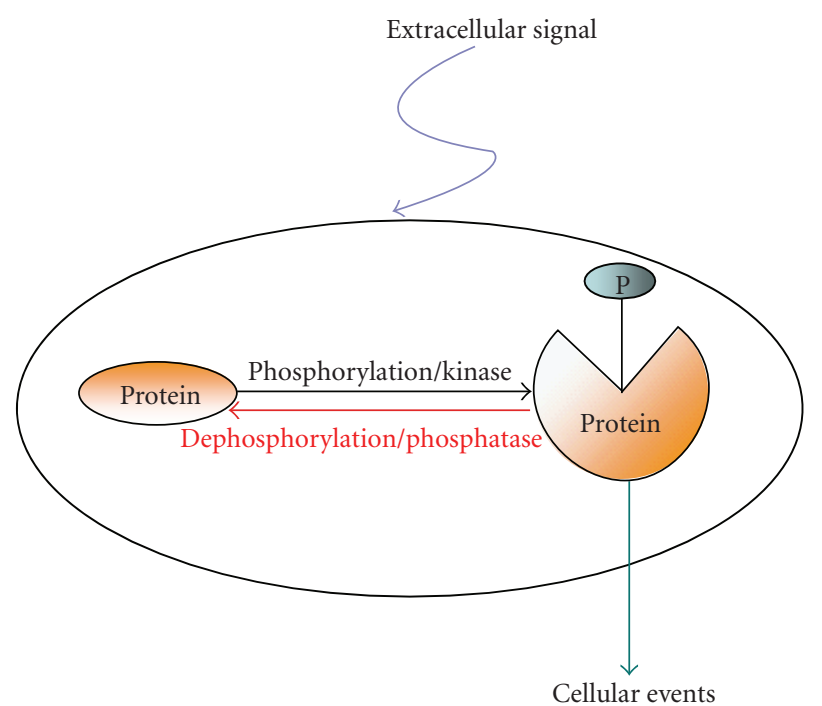

Figure 1: General principles of signal regulation by kinases and Phosphatases: the phosphorylation and dephosphorylation of the protein, the former being catalyzed by a kinase, and the latter by a phosphatase. Phosphorylation usually causes a conformational change in the protein.

mice fail to develop a Th1 response and are susceptible to Leishmania infection [9]. The susceptibility to Leishmania infection can be prevented by IL-12 administration in these mice suggesting that CD40-CD154 interaction is required for the production of IL-12, which polarizes the Th cells to Th1 type [9-11]. Thus, the host-protective function of CD40 was attributed to setting a Th1 bias $[9,10,12]$. Beside their role in Th1 immune response, CD40-CD40L interactions were also shown to stimulate macrophages to produce a number of cytokines and inflammatory mediators including nitric oxide (NO), which plays a key role in parasite killing [13]. As CD40-L binds to CD40, it triggers the signal through several signaling intermediates [14] to result in mitogen-activated protein kinase (MAPK) phosphorylation $[15,16]$. The MAP kinases play an important role as signal kinases and their activity is elicited upon phosphorylation of threonine and tyrosine residues in a Thr-X-Tyr motif in their regulatory domain and thereby controls the activation status of transcription factors [17]. There are three major groups of MAP kinases in mammalian cells-the extracellular signal-regulated protein kinases (ERK) [18], the p38MAP kinases [19], and the c-Jun NH2-terminal kinases (JNK) [20]. MAPKs phosphorylate selected intracellular proteins, including transcription factors, which subsequently regulate gene expression by transcriptional and posttranscriptional mechanisms [21]. Each of these kinases is regulated by other upstream kinases [22]. These three families of MAPKs form three parallel signaling cascades activated by distinct or sometimes overlapping sets of stimuli. Activated by mitogens and growth factors, the ERKs mediate signals promoting cell proliferation, differentiation, and survival. JNK and p38 MAPKs are predominantly activated not only by stress such as osmotic changes and heat shock but also by inflammatory cytokines TNF- $\alpha$ and IL-1 $\beta$ and bacterial lipopolysaccharide (LPS) [23-25].

Several studies show that MAPKs are actively repressed and cannot be activated when Leishmania-infected macrophages are stimulated with a variety of agonists. Inhibition of MAPK phosphorylation resulted in less expression of IL-12 and iNOS2 (inducible nitric oxide synthetase type 2), the enzyme that catalyzes the production of NO $[26,27]$ which has been shown to play crucial role in the development of immunity to Leishmania [28]. In naive macrophages, Leishmania donovani promastigotes failed to activate the phosphorylation of p38 MAPK, ERK1/2, and JNK, as well as the degradation of I $\kappa \mathrm{B}-\alpha[29]$ affecting the activation of proinflammatory cytokines. The parasite surface molecule LPG has been implicated in the inactivation of MAPKs, since phagocytosis of LPG-deficient L. donovani promastigotes caused MAPK activation, without the requirement for subsequent macrophage stimulation [29].

One of the studies showed that ERK and p38 MAPKs play differential roles in the regulation of LPS-stimulated inducible NO synthase and IL-12 gene expression [30]. LPS stimulated ERK, JNK, and p38 MAP kinases in J774 macrophages but with different activation kinetics. It was also demonstrated that p38 plays an essential role in the induction of inducible NO synthase, and ERK MAP kinases play only a minor role in promoting $\mathrm{NO}$ generation by using inhibitors selective for ERK (PD98059) and p38 (SB203580). It was also demonstrated that synthetic Leishmania lipophosphoglycans act by stimulating ERK MAP kinase to inhibit macrophage IL-12 production thus promoting parasite survival and thus underlining the physiological relevance of these regulatory signals [30].

In addition, the CD40-induced p38MAPK phosphorylation, iNOS2 expression, and antileishmanial function were impaired in Leishmania-infected macrophages but were restored by anisomycin, a p38MAPK activator, suggesting a crucial role of p38MAPK in CD40 signaling. Anisomycin's effects were reversed by SB203580, a p38MAPK-specific inhibitor, emphasizing the role of p38MAPK in CD40induced iNOS2-dependent leishmanicidal function. Thus anisomycin's ability to restore CD40 signaling and eliminate amastigotes not only highlighted the susceptibility of amastigotes to killing after p38MAPK activation but also suggested a potential use of anisomycin as an antileishmanial drug [31].

While interference with CD40-induced p38MAPK is consistent with the general suppressive scheme of parasitism, the observation does not explain the CD40-induced IL10 production from macrophages [32] and increased IL10 production from Leishmania-infected macrophages [33]. Since IL-10 is a suppressive cytokine, these observations support the proparasitic role of IL-10 but contradict our results. This is because Leishmania interference with the CD40 signaling through MAPK, if it were associated with IL10 production as well, would inhibit IL-10 production and clearly, that was not the case. So, it is possible that there are other signaling pathways or MAPKs carrying the CD40 signal and associate with IL-10 production. Indeed, it was observed 


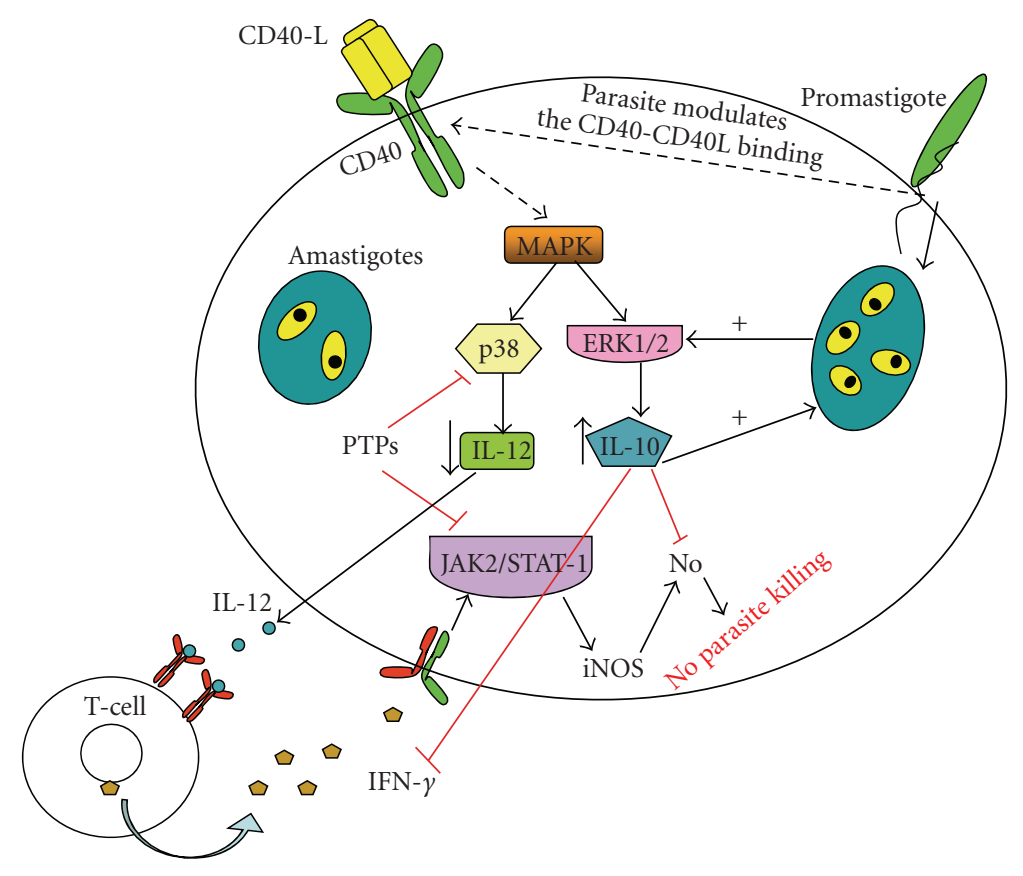

Figure 2: Modulation of CD40 responsiveness in Leishmania-infected macrophages: crosslinking of anti-CD40 antibody activates p38 MAPK-induced leishmanicidal function via iNOS2 induction. Leishmania infection downregulates CD40-induced p38 MAPK phosphorylation and uses the capability of this receptor to signal along an ERK1/2-dependent pathway to produce the proparasitic Th2 cytokine IL-10 from macrophages. iNOS2: inducible nitric oxide synthase 2; NO: nitric oxide; PTP: Protein tyrosine phosphatases.

that CD40 induced ERK-1/2 activation, inhibition of which resulted in decreased CD40-induced IL-10 production [21]. In Leishmania-infected macrophages, CD40-induced ERK$1 / 2$ activation was increased suggesting a reciprocal interaction between the p38MAPK and ERK-1/2 activation [34]. Indeed, inhibition of one MAPK activated the other MAPK. In macrophages, higher strengths of stimulation induced p38MAPK phosphorylation but weaker strengths resulted in ERK-1/2 phosphorylation [34]. During Leishmania infection, the level of CD40-induced ERK1/2 phosphorylation and IL-10 production increases, whereas p38MAPK activation and IL-12 production decrease, demonstrating a reciprocal modulation of the CD40 signaling pathway by the parasite [34] (Figure 2). IL-10 produced during the infection inhibits CD40-induced IL-12 production by impairing p38MAPK activation [34]. Neutralization of CD40-induced IL-10 enhances the antileishmanial functions of CD40. Thus, the anti-leishmanial function of CD40 is self-limited by induction of IL-10. The work of Yang et al. also demonstrated a critical role for ERK activation in the induction of IL10 production by Leishmania and showed that parasite immune complexes bind to macrophage $\mathrm{Fc} \gamma \mathrm{R}$ and induce this activation via the macrophage $\mathrm{F} c \gamma \mathrm{R}$ [35].

Although first observed in Leishmania infection in macrophages, the same principle of differential CD40 signaling holds true in dendritic cells and in tumor models [36-38]. In one study it was shown that infection with L. amazonensis amastigotes inhibited the ability of DCs to undergo proper maturation in vivo characterized by significantly low CD40 surface expression and significantly decreased IL-12p40 production through activation of the MAP kinase ERK1/2 [39].

While the differential CD40 signaling and its selective manipulation by Leishmania solved the apparent paradox of inducing counteractive cytokines by CD40 stimulation, the question remained to be solved is how a single receptor induces reciprocal signaling pathways and counteractive effector functions. We have shown that such differential signaling depends on the composition of the signalosomes assembled on the membrane. When CD40 binds TRAF-2,3,5, it signals primarily through p38MAP kinase whereas binding to TRAF-6 signals primarily through ERK-1/2. We have shown that cholesterol influences the assembly of distinct CD40 signalosomes. Depletion of membrane cholesterol inhibited the assembly of the p38MAP kinase inducing CD40 signalosome but enhances the ERK-1/2 activation [40]. Consistent with these observations, Leishmania is found to deplete membrane cholesterol and enhance CD40 binding to TRAF-6 [40]. However, how Leishmania interferes with macrophage cholesterol metabolism remains to be elucidated.

It was demonstrated that the Leishmania surface molecule, lipophosphoglycan, stimulates the activation of ERKs, JNK, and the p38 MAP kinase simultaneously but with differential kinetics in J774A.1 macrophage cell line. It was shown that both p38 and ERK MAP kinase activation appears to be necessary for AP-1 activation by LPG and it also induced IL-12 production and generation of nitric oxide demonstrating that $L$. donovani LPG activates proinflammatory, endotoxin-like response pathway in J774A.1 
macrophages [41]. A recent report [42] pointed to the importance of the metalloprotease GP63 in regulating several important signaling proteins, contributing to downstream changes in global protein tyrosine phosphorylation levels as well as a specific effect on p38 MAPK activation. p38 was inactivated upon infection in a GP63-and protein degradation-dependent manner, which likely involves cleavage of the upstream adaptor TAB1 [42].

2.2. TLR Responsiveness. Of the growing number of receptors involved in the recognition of pathogen-associated molecular patterns (PAMPs) [43], TLRs are considered key players of the innate immune response [44, 45]. This family of receptors is comprised of thirteen members that recognize most of the molecular patterns on pathogens. The recognition of the ligands results in the secretion of inflammatory mediators such as TNF- $\alpha$ and IL-12 as well as the induction of iNOS2 expression [45-47], leading to host protection.

Following the recognition of a PAMP, the adaptor myeloid differentiation factor 88 (MyD88) is recruited to the TIR (toll-interleukin 1 receptor) domain of the TLR [48]. Next, IL-1 receptor-associated-kinase-1 (IRAK-1) is recruited to the complex and is phosphorylated by IRAK4 and by autophosphorylation. IRAK-1 dissociates from MyD88 to interact with TRAF6 and activates various cascades, ultimately leading to the activation of MAP kinase pathways, the translocation of NF- $\kappa \mathrm{B}$ to the nucleus as well as the secretion of proinflammatory cytokines $[49,50]$. Another pathway, termed "MyD88-independent", is implicated in signaling following engagement of TLR3 and TLR4. This cascade uses TRIF as an adaptor protein and allows the translocation of NF- $\kappa \mathrm{B}$ to the nucleus and the activation of MAP kinase pathways with a slower kinetics as well as the activation of IP-10 and IFN- $\alpha / \beta$ via the activation of IRF3 $[51,52]$.

Substantial studies demonstrated that different receptors mediate the uptake and phagocytosis of Leishmania $s p p$. by macrophages, although the initial signaling events are unknown [53]. As LPG of Leishmania promastigotes interacts with NK cell-expressed TLR2 [54], it is possible that the leishmanial LPG may interact with the macrophage expressed TLR2 and modulates cellular functions to ensure its survival within the host cell. For example, L. majorinduced IL- $1 \alpha$ expression was substantially decreased in MyD88-deficient mice [55]. Similarly, the genetically resistant C57BL/6 mice became susceptible to Leishmania parasite in absence of MyD88 due to increased level of IL-4 and decreased level of IFN- $\gamma$ and IL-12p40 [56]. Furthermore, silencing of TLR2, TLR3, IRAK-1, and MyD88 expression by RNA interference also revealed the involvement of both TLR 2 and TLR 3 in the production of NO and TNF- $\alpha$ by macrophages in response to $L$. donovani promastigotes [57]. TLR2-mediated responses are dependent on $\operatorname{Gal} \beta 1,4 \mathrm{Man} \alpha$ $\mathrm{PO}_{4}$ containing phosphoglycans, whereas TLR3-mediated responses are independent of these glycoconjugates. TLR3 also plays a role in the leishmanicidal activity of the IFN$\gamma$-primed macrophages [57]. It is quite possible that Leishmania may modulate MyD88 expression and recruitment to
TLRs resulting in altered TLR responsiveness of the infected macrophages.

An impaired resistance to L. major was also reported in TLR4-deficient mice. Compared to wild type controls, the growth of parasites in the cutaneous lesions was drastically increased in mice from a resistant background carrying a homozygous mutation of the thr 4 gene (TLR4 e/e) as early as one day after inoculation of $L$. major. Later in the infection, an enhanced arginase activity leads to the production of compounds essential for parasite proliferation in macrophages and its increase in mutant mice indicating that TLR4 signaling could enhance the microbicidal activity of macrophages harboring parasites [58]. Results from studies comparing TLR4 deficient mice with TLR4 and IL-12 $\beta 2$ double deficient mice suggested an IL-12 independent role of TLR4 in anti-Leishmania immunity [59]. The IL-12 dependent NK cell IFN- $\gamma$ response was severely compromised in TLR9-deficient mice as well. In studies with $L$. infantum infection, in mature dendritic cells- (mDCs-) depleted mice, the IFN- $\gamma$ response was abolished due to low IL-12 production that could be rescued by $\mathrm{CpG}$ and IL-12 [60]. L. major is also shown to modulate TLR9 signaling for activating NK cells [61]. Likewise, L. donovani infection caused suppression of TLR2and TLR4-stimulated IL-12p40, with an increase in IL10 production in cells of monocyte/macrophage lineage by suppressing p38MAPK phosphorylation and activating ERK$1 / 2$ phosphorylation through a contact-dependent mechanism [62]. These studies imply how Leishmania modulates the TLR responsiveness that might help their survival in macrophages.

2.3. IFN- $\gamma$ Receptor Responsiveness. It is widely accepted that IFN- $\gamma$ plays a critical role in controlling Leishmania infection by inducing macrophage leishmanicidal activity as well as by favoring Th1 development [63, 64]. The biological functions of IFN- $\gamma$ are mediated via IFN- $\gamma$ R(IFN- $\gamma$ receptor-) mediated pathway involving receptorassociated kinases JAK1/JAK2 and STAT-1 [65, 66]. IFN$\gamma$ binding to the receptor activates JAK1/JAK2 kinases and phosphorylates STAT-1, which translocates to the nucleus and enhances transcription of IFN- $\gamma$-induced genes to increase macrophage microbicidal activity (Figure 3 ). IFN$\gamma \mathrm{R}$ is comprised of IFN $-\gamma \mathrm{R} \alpha$ and IFN $-\gamma \mathrm{R} \beta$ chains. While IFN- $\gamma \mathrm{R} \alpha$ chain plays a critical role in ligand binding, IFN$\gamma \mathrm{R} \beta$ is required for IFN- $\gamma$ signal transduction [67]. The critical role of IFN- $\gamma \mathrm{R}$ in development of IFN- $\gamma$-mediated host immunity is evident in studies showing that IFN$\gamma \mathrm{R}^{-/-}$mice are highly susceptible to pathogens such as Mycobacterium avium [68], Listeria monocytogenes [69], Candida albicans [70], and Plasmodium berghei [71]. It has been shown that IFN- $\gamma \mathrm{R}^{-/-}$mice are highly susceptible to high as well as low dose $L$. major infection indicating that IFN $-\gamma \mathrm{R}$ is essential for control of cutaneous leishmaniasis [72]. L. donovani has also been shown to attenuate IFN$\gamma \mathrm{R}$ expression in human monocytes [73]. Some of the important macrophage functions suppressed by Leishmania which are IFN- $\gamma$ inducible are NO production, MHC class II expression. One of the major results of Leishmania infection 


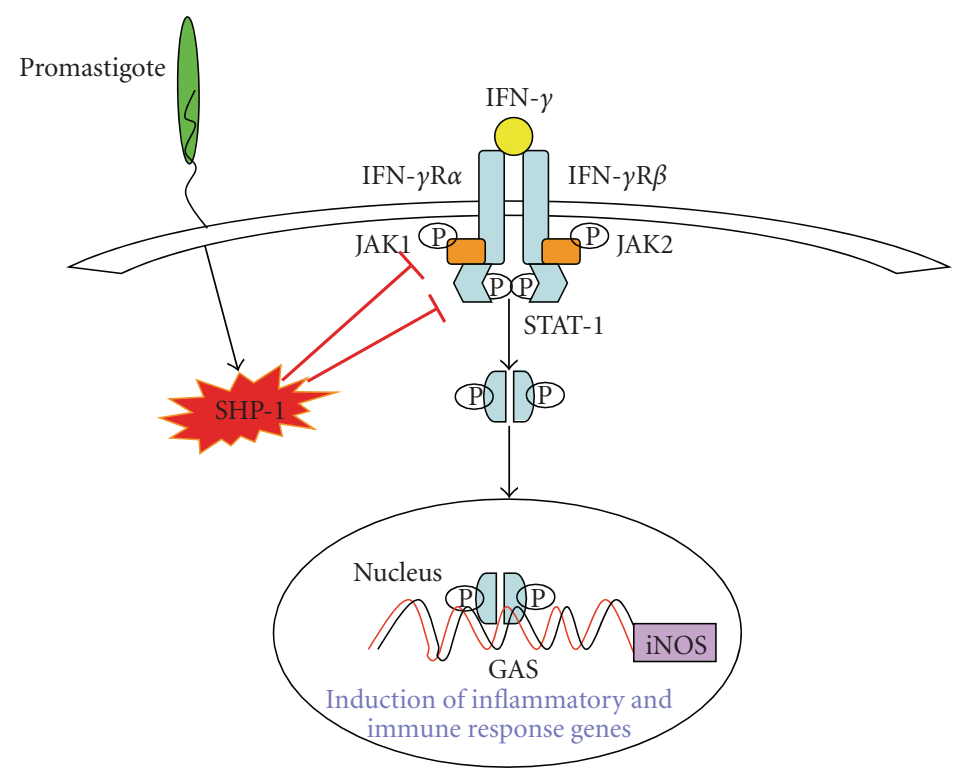

FIGURE 3: STAT1 phosphorylation regulation through IFN $\gamma$ receptor: infected macrophages display reduced levels of total and phosphorylated JAK1 and JAK2 and attenuate IFN- $\gamma$ induced STAT-1 phosphorylation in macrophages, aiding the parasites in escaping host immunity. GAS: Interferon gamma-activated site.

is the inhibition of the JAK2/STAT1 signaling cascade. Infected macrophages show defective phosphorylation of JAK1, JAK2, and STAT1 on IFN- $\gamma$ stimulation $[73,74]$. This inactivation depends on the activation of phosphotyrosine phosphatases (PTPs), in particular the PTP, SHP-1. One study has shown that inactivation of JAK2/STAT1 is caused by the negative regulation of the IFN- $\gamma$ receptor in infected cells [75]. However, this was not observed following L. amazonensis amastigote infection, where IFN$\gamma$-dependent regulation of MHC class I was not affected by infection, indicating that the primary signaling lesion lays downstream of the IFN- $\gamma$ receptor [76]. Certain bacterial and viral pathogens have been shown to evade host immunity by downregulating IFN- $\gamma \mathrm{R} \alpha$ expression on effector cells [7779]. Similarly, both L. major and L. mexicana suppressed IFN $-\gamma \mathrm{R} \alpha$ and IFN- $\gamma \mathrm{R} \beta$ expression, reduced levels of total Jak1 and Jak2, and downregulated IFN- $\gamma$-induced Jak1, Jak2, and STAT1 activation, with the effects more profound with $L$. mexicana infection than $L$. major. In addition $L$. mexicana preferentially enhanced tyrosine phosphorylation of dominant negative STAT1 $\beta$, which may be one of the several survival mechanisms used by this parasite to evade the host defense mechanisms [80]. Recently it was shown that infection of DCs with $L$. amazonensis parasites resulted in multiple alterations in innate signaling pathways, including a protease- and proteosome-dependent decreased phosphorylation of STAT1, 2, 3 and ERK1/2, and markedly reduced expression of interferon regulatory factor-1 (IRF-1) and IRF8. Furthermore, it was shown that alterations in intracellular signaling and suppression of IL-12 production were caused by direct effects of amastigotes rather than by the induction of endogenous IL-10 [81].
2.4. IL-10 Receptor Responsiveness. IL-10 is a homodimer with 160aa and belongs to class II $\alpha$-helical cytokine. IL-10 is produced by many cell types including T cells, monocytes, and macrophages. IL-10 interacts with its tetrameric receptor complex consisting of two IL-10R1 and two IL-10R2 polypeptide chains [82]. IL-10 is a potent immunosuppressant of macrophage functions, suppresses the production of proinflammatory cytokines by activated monocytes/macrophages, and enhances B lymphocyte proliferation and antibody secretion. IL-10 decreases expression of MHC classes I and II affecting antigen presentation [83] and reduces the transcription and translation of proinflammatory cytokines TNF $\alpha$, IL-12, and IL-18 from macrophages [84]. IL-10 also suppresses the induction of iNOS2 that catalyzes the production of NO, the leishmanicidal free radical [85-87]. IL-10 affects T cells mostly in an indirect manner, by its effects on antigen presenting cells [88].

IL-10 is a critical cytokine in determining the host susceptibility to Leishmania infection. In murine models of cutaneous [89] and visceral [90] leishmaniasis, IL-10 contributes to disease progression. IL-10-deficient or antiIL-10 receptor antibody-treated mice are relatively resistant to Leishmania infection [91], while the administration of exogenous IL-10 [92] or the induction of endogenous IL10 exacerbates the disease [93]. It has been reported that the susceptibility of BALB/c mice to $L$. major infection is dependent on IL-10 as IL-4R alpha ${ }^{-/}$BALB/c mice, despite the absence of IL-4/IL-13 signaling remains highly susceptible to L. major infection [94]. Similarly, the IL-10 levels in patients with $L$. donovani infection directly correlate with the disease severity [95]. 
It was demonstrated that macrophage IL-10 is turnedon by Leishmania amastigotes itself and the virulence factor responsible for this induction was found to be host IgG [33]. The host IgG present on the surface of Leishmania amastigotes interacts with $\mathrm{Fc} \gamma \mathrm{R}$ on the surface of macrophage to trigger signaling events that leads to the induction of IL-10; however, unopsonised amastigotes fail to do so. IL-10 produced by infected macrophages prevents macrophage activation and thus inhibits production of proinflammatory cytokine IL-12 and TNF $\alpha$. Fc $\gamma$ R KO (mice lacking all Fc $\gamma$ Rs) mice similar to IL-10 KO mice are resistant to L. mexicana infection and also control parasites as a result of strong IFN $\gamma$ response [96]. Ligation of Fc $\gamma \mathrm{R}$ on macrophages with IgG on the parasite surface induces IL-10, which in turn suppresses IFN $\gamma$ response and NO production in L. mexicana infection. Further it was also shown that Fc $\gamma$ R III is crucial for macrophage to produce IL-10 and disease progression in L. mexicana infection [97].

MAPK ERK1/2 has been shown to be involved in induction of IL-10 from macrophages [35]. IgG opsonised amastigotes interact with $\mathrm{Fc} \gamma \mathrm{R}$ on macrophages to induce ERK1/2 activation. The hyperactivation of ERK1/2 results in histone $\mathrm{H} 3$ phosphorylation of IL-10 promoter making the promoter accessible to transcription factor, and the result is secretion of high levels of inhibitory cytokine IL-10. However lesion-derived amastigotes alone are not sufficient to induce IL-10; despite their activity to rapidly activate ERK1/2, some inflammatory signal is required for induction of IL10. This inflammatory stimulus can be small fragments of hyaluronan called as LMW-HA which is a major component of extracellular matrix. Also leishmanial lesions are generally superinfected with bacteria which can provide inflammatory signal through TLR2 or 4 . Role of ERK1/2 MAPK in inducing IL-10 has also been demonstrated in CD40-CD40L interaction; lower dose of anti-CD40 stimulation induces more ERK1/2 MAPK phosphorylation and IL-10 secretion in L. major infection while inhibition of ERK1/2 reduces CD40 induced IL-10 secretion and disease progression [34].

The IL-10/IL-10R interaction engages the phosphorylation and activation of receptor-associated janus tyrosine kinases, JAK1 and Tyk2, which in turn phosphorylate transcription factor STAT3. It then homodimerizes and translocates to the nucleus where it binds with high affinity to STAT-binding elements (SBEs) in the promoters of various IL-10-responsive genes [98]. STAT3 plays a dominant mediator of majority of IL-10 functions [99]. Overexpression of dominant negative STAT3 suppresses the IL-10 promoter activity while wild type STAT3 leads to enhancement of this activity [100]. The anti-inflammatory functions of IL-10 are STAT3 dependent as in STAT3 deficient murine macrophages IL-10 is unable to suppress LPS-induced TNF- $\alpha$ and IL- 6 production [101, 102]. In human macrophages, IL-10 rapidly induces SOCS3 protein expression and this expression requires STAT3 as STAT3 dominant negative human macrophages failed to induce IL-10-mediated SOCS3 expression [103].

\section{Alterations of Host Cell Kinases and Phosphatases by Leishmania}

3.1. Protein Kinase C. PKC, serine-threonine kinases with several isoforms are involved in a wide variety of immune cell functions and are classified as classical, novel, and atypical PKC depending on their structure and cofactor requirement [104]. A number of studies have implicated PKC in the control of host defense against intracellular infections. Indeed, Leishmania infection inhibits PKC activation and subsequent intracellular signaling. PKC-dependent oxidative burst activity and protein phosphorylation were found to be markedly attenuated in Leishmania-infected human monocytes [105]. Promastigote LPG has been shown to inhibit PKC activation and PKC-dependent phosphorylation of both the PKC-specific VRKRTRLLR substrate peptide and MARCKS (Myristoylated alanine-rich C kinase substrate) [106]. Another PKC substrate protein, MRP (MARCKS-related protein), levels were also found to be decreased in infection with all species or strains of Leishmania parasite, including lipophosphoglycan-deficient L. major L119 [107]. LPGmediated inhibition of PKC activation may be due to the ability of LPG to interfere with binding of regulators, including $\mathrm{Ca}^{2+}$ and diacyl glycerol; in addition LPG can also block PKC membrane insertion [108]. LPG also inhibits phagosomal maturation, by inhibiting PKC- $\alpha$ dependent depolymerization of periphagosomal F-actin $[109,110]$. Further infection with L. major inhibited PKC-dependent c-fos and TNF $\alpha$ gene expression [111]. L. donovani infection selectively inhibited $\mathrm{Ca}^{2+}$-dependent PKC activity but $\mathrm{Ca}^{2+}$-independent PKC activity was enhanced. Leishmania infection reduced the $\mathrm{Ca}^{2+}$-dependent PKC isoform-PKC $\beta$-expression whereas expression of PKC zeta, a $\mathrm{Ca}^{2+}$-independent $\mathrm{PKC}$ isoform, was enhanced [112]. This decrease in $\mathrm{Ca}^{2+}$-dependent PKC activity can be due to IL-10 produced by $L$. donovani infection as pretreatment with anti-IL-10 neutralizing antibody significantly restored $\mathrm{Ca}^{2+}$-dependent PKC activity [113]. Infection of macrophages with L. donovani enhanced the level of intracellular ceramide largely due to its de novo synthesis and the enhanced ceramide was found to be responsible for the downregulation of classical PKC activity, upregulation of $\mathrm{Ca}^{2+}$-independent atypical PKC-zeta expression, and activity of calcium independent PKC [114]. Also C-C chemokines particularly macrophage inflammatory protein- (MIP-) 1 alpha and macrophage chemoattractant protein- (MCP-) 1 were found to restrict the parasitic burden via the regulation of impaired PKC signaling and induction of free-radical generation in murine leishmaniasis. These chemokines restored $\mathrm{Ca}^{2+}$-dependent PKC activity and inhibited $\mathrm{Ca}^{2+}$-independent atypical PKC activity in L. donovani-infected macrophages under both in vivo and in vitro conditions [115]. de Almeida-Amaral et al. reported the presence of protein kinase C-like (PKClike) protein in L. amazonensis and found that this PKClike protein is activated by phorbol ester (PMA) and has both calcium dependent and independent PKC-like activity. Further they studied the role of this PKC-like protein in modulation of promastigotes $\left(\mathrm{Na}^{++} \mathrm{K}^{+}\right)$ATPase activity and found that activation of $\mathrm{Ca}^{2+}$-dependent $\mathrm{PKC}$-like protein 


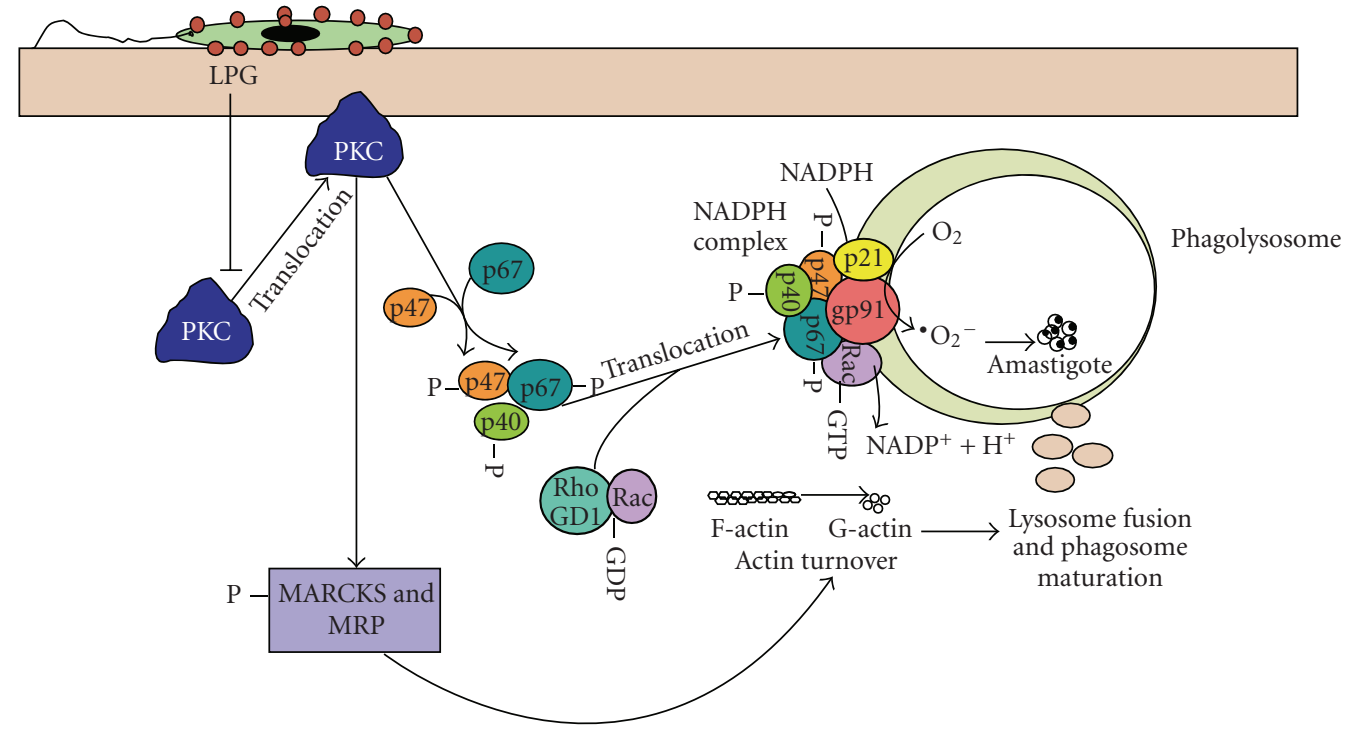

FIGURE 4: PKC regulation in Leishmania infected macrophages: LPG of Leishmania inhibits PKC activation and translocation to the membrane. PKC is responsible for phosphorylation of p47phox and p67phox components of NADPH oxidase which are subsequently translocated to phagosomal membrane to form NADPH oxidase complex, which is responsible for superoxide anion generation and hence parasite killing. Further PKC phosphorylates myristoylated alanine-rich C kinase substrate (MARCKS) and MARCKS-related protein (MRP) which are involved in actin turnover and finally in phagosomal maturation and lysosomal fusion resulting in parasite killing. As PKC activation is inhibited by Leishmania, this results in subsequent inhibition of all the above mentioned processes thereby favoring parasite survival.

increased $\left(\mathrm{Na}^{++} \mathrm{K}^{+}\right)$ATPase activity while activation of $\mathrm{Ca}^{2+}{ }_{-}$ independent PKC-like protein has inhibitory effect [116]. Recently a study by the same group reported presence of ecto-PKC in different Leishmania species. They found higher PKC activity in infective stationary stage of Leishmania promastigotes and that this PKC-like plays a critical role in attachment and internalization steps involved in the parasite invasion process [117]. Some of the Leishmania-PKC interactions are summarized in Figure 4.

3.2. Other Kinases. PI3K signaling activated by Leishmania infection is a negative signaling pathway which helps in progression of disease. It has been shown that PI3K signaling negatively regulates IL-12 production and inhibition of PI3K signaling by specific inhibitor or its downstream kinase Akt reverses the IL-12 blockade in macrophages [118]. PI3K $\mathrm{K}^{-/-}$ DCs show enhanced IL-12 production and $\mathrm{PI} 3 \mathrm{~K}^{-/-}$mice elicit an enhanced Th1 response upon $L$. major infection [119].

\section{Modulation of Phosphatases}

Leishmania can also activate various molecules that inhibit intracellular signaling cascades (Figure 5) thereby evading host immune machinery to inhibit immune responses.

4.1. SHP-1 Protein Tyrosine Phosphatase. An important negative regulatory molecule of numerous signaling pathways, such as those related to the actions of interferons [120, 121], erythropoietin $[122,123]$, and many others, is SHP-1 (Src homology 2 domain containing tyrosine phosphatase) which is expressed principally in haematopoietic cells but also in smooth muscle [124] and epithelial cells [125]. Many of the interactions of SHP-1 with its substrates involve the binding of either one or both of its tandem SH2 domains to tyrosine phosphorylated, immunoreceptor tyrosine-based inhibitory motifs (ITIMs). These specialized motifs are known to be present in many signaling molecules [126, 127]. Multiple types of ITIMs exist and display-specific abilities to recruit and activate $\mathrm{SH} 2$ containing PTPs.

SHP-1 is responsible for the negative regulation of many signaling pathways in all hematopoietic cell types, by acting in a variety of fashions. For instance, SHP-1 can bind to receptors and dephosphorylate them directly; it can also associate with a receptor and dephosphorylate other members of the receptor binding complex. The PTP can also interact with other cytosolic proteins and tyrosine dephosphorylates them or their associated proteins [126]. Macrophages infected with Leishmania in vitro have elevated SHP-1 activity as well as total PTP activity, resulting in widespread dephosphorylation of high-molecular-weight proteins [74]. Furthermore, infection causes colocalization of SHP-1 and JAK2 and prevents tyrosine phosphorylation of JAK2 in response to IFN- $\gamma$ [74]. Dephosphorylation of JAK $1 / 2$, TYK 2 , and STAT $1 \alpha,-2,-3,-5 \alpha / \beta$, and -6 has already been documented [121-123, 128, 129]. Forget et al. showed that activation of the host PTP SHP-1 is responsible for the dephosphorylation and inactivation of ERK1/2, as SHP-1deficient macrophages showed normal JAK2 and ERK1/2 activity following infection with $L$. donovani, and responded to IFN $\gamma$ by increased NO production [130]. 


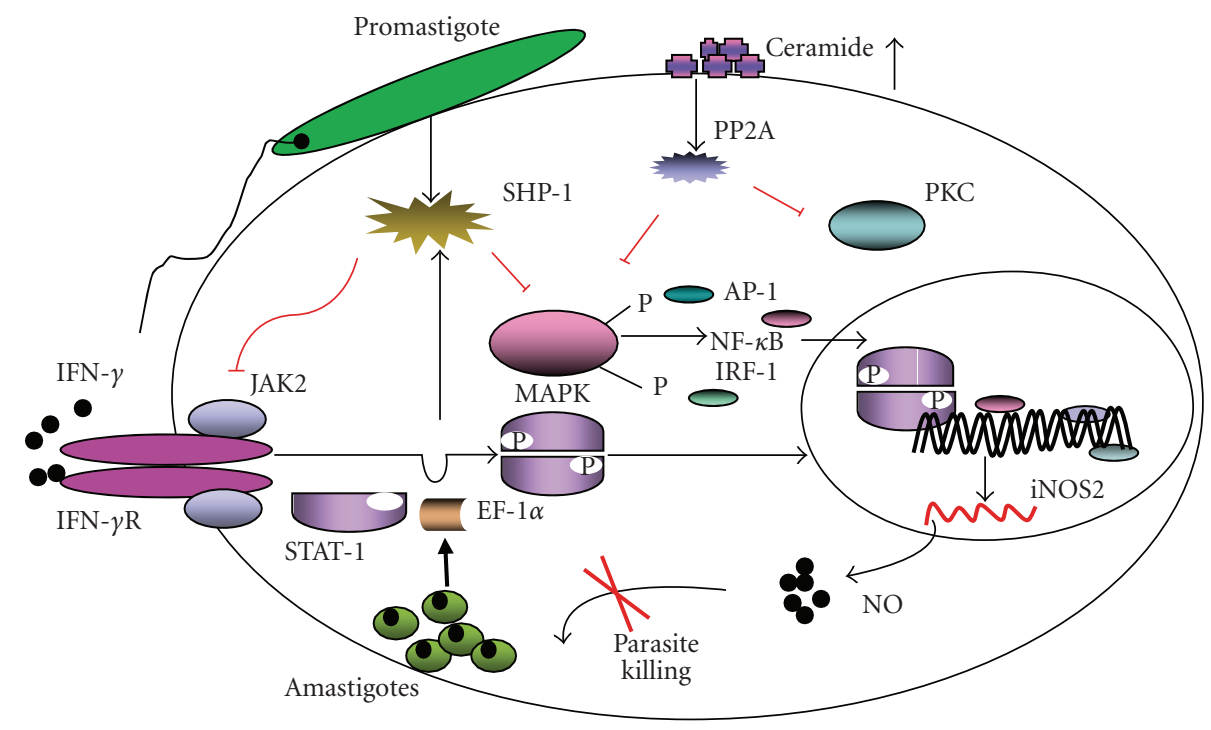

FIGURE 5: MAPK phosphorylation in Leishmania-infected macrophages: Leishmania infection of macrophages represses the most important MAPK family members: ERK1/2, p38, and JNK. MAPK inactivation is accompanied by inhibition of transcription factors Elk-1, c-fos, IRF-1, $\mathrm{AP}-1$, and NF- $\kappa \mathrm{B}$ and IFN- $\gamma$-dependent NO generation.

In viable motheaten mice, whose SHP-1 phosphatase activity is deficient, increased nuclear translocation of the transcription factor NF- $\kappa$ B has been reported $[131,132]$, which seems to provoke an exacerbated inflammatory response. Macrophages derived from SHP- $1^{-/-}$mice show elevated iNOS induction and NO generation and are more efficient at killing Leishmania [133]. This is reflected in vivo by increased NO generation and reduced parasite load in both SHP-1-deficient mice and mice treated with chemical PTP inhibitors like peroxovanadium [133-135]. Some studies have demonstrated that the inhibition of IFN$\gamma$-dependent phosphorylation cascades following infection is due to activation of host cell tyrosine phosphatases [74, 134]. This was associated with a phenotype of cell deactivation in which MAP kinase signaling, c-FOS, and iNOS expression were each defective. Importantly, inhibition of phosphotyrosine phosphatase activity with sodium orthovanadate before infection prevented development of the deactivated phenotype [136]. Studies aimed at understanding the mechanism responsible for the change in activation state of SHP-1 led to the identification of Leishmania EF- $1 \alpha$ as a modulator of host SHP-1 and also suggesting it to be a novel virulence factor contributing to macrophage deactivation [137].

Recently one study revealed that upon Leishmania infection, SHP-1 is able to rapidly bind to and inactivate a critical kinase (IRAK-1) in TLR signaling pathway. This regulatory binding was shown to be mediated by an evolutionarily conserved motif identified in the kinase. This motif was also present in other kinases involved in Toll signaling and therefore could represent a regulatory mechanism of relevance to many kinases. This work reports a unique mechanism by which Leishmania can avoid harmful TLR signaling [138].
4.2. Other Phosphatases. Ceramide is also capable of activating protein phosphatases such as protein phosphatase 1 (PP1) and PP2A [139-141]. It is through these protein phosphatases that ceramide inhibits kinases such as the classical as well as novel PKC isoforms and Akt [138-142]. It was observed that endogenous ceramide generated during leishmanial infection led to the dephosphorylation of protein kinase B (Akt) in infected cells. Ceramide induced the PKC $\zeta$ Akt interaction along with the serine/threonine phosphatase PP2A [143].

However a phosphosphotyrosine phosphatase PTEN (phosphatase and tensin homologue deleted on chromosome ten) is reported to play a protective role against $L$. major infection as the mice lacking PTEN are more susceptible to the infection than the WT mice. PTEN deficient macrophages have reduced ability to kill parasites in response to IFN $-\gamma$ treatment, showing decreased TNF- $\alpha$ production, iNOS expression, and NO secretion but more IL-10 secretion than WT cells. Thus the study shows that phosphatase PTEN is required for efficient clearance of intracellular parasite in macrophages [144].

\section{Conclusion}

There are multiple ways by which intracellular pathogens like Leishmania make use of host cell's machinery in order to survive and replicate. One such mechanism is the distortion of host macrophage's own signaling pathways to selectively repress or enhance the expression of various cytokines and microbicidal molecules and antigen presentation. The interplay between various signaling molecules is complex. As signaling pathways can be pharmacologically manipulated, a better knowledge of their role and the mechanisms whereby 
they regulate host immune cell functions and pathogen growth should permit the development of new therapies to control infectious agents.

\section{Acknowledgment}

The work was financially supported by the Department of Biotechnology, Government of India, New Delhi, India.

\section{References}

[1] F. Y. Liew and C. A. O’Donnell, "Immunology of leishmaniasis," Advances in Parasitology, vol. 32, pp. 161-259, 1993.

[2] N. E. Reiner, "Altered cell signaling and mononuclear phagocyte deactivation during intracellular infection," Immunology Today, vol. 15, no. 8, pp. 374-381, 1994.

[3] S. M. Beverley, "Hijacking the cell: parasites in the driver's seat," Cell, vol. 87, no. 5, pp. 787-789, 1996.

[4] H. Sun and N. K. Tonks, "The coordinated action of protein tyrosine phosphatases and kinases in cell signaling," Trends in Biochemical Sciences, vol. 19, no. 11, pp. 480-485, 1994.

[5] T. Hunter, "Protein kinases and phosphatases: the yin and yang of protein phosphorylation and signaling," Cell, vol. 80, no. 2, pp. 225-236, 1995.

[6] M. Olivier, D. J. Gregory, and G. Forget, "Subversion mechanisms by which Leishmania parasites can escape the host immune response: a signaling point of view," Clinical Microbiology Reviews, vol. 18, no. 2, pp. 293-305, 2005.

[7] A. Miga, S. Masters, M. Gonzalez, and R. J. Noelle, "The role of CD40-CD154 interactions in the regulation of cell mediated immunity," Immunological Investigations, vol. 29, no. 2, pp. 111-114, 2000.

[8] C. L. Ren, T. Morio, S. M. Fu, and R. S. Geha, "Signal transduction via CD40 involves activation of lyn kinase and phosphatidylinositol-3-kinase, and phosphorylation of phospholipase C $\gamma 2$," Journal of Experimental Medicine, vol. 179, no. 2, pp. 673-680, 1994.

[9] M. Kamanaka, P. Yu, T. Yasui, et al., "Protective role of CD40 in Leishmania major infection at two distinct phases of cellmediated immunity," Immunity, vol. 4, no. 3, pp. 275-281, 1996.

[10] K. A. Campbell, P. J. Ovendale, M. K. Kennedy, W. C. Fanslow, S. G. Reed, and C. R. Maliszewski, "CD40 ligand is required for protective cell-mediated immunity to Leishmania major," Immunity, vol. 4, no. 3, pp. 283-289, 1996.

[11] L. C. C. Afonso, T. M. Scharton, L. Q. Vieira, M. Wysocka, G. Trinchieri, and P. Scott, "The adjuvant effect of interleukin12 in a vaccine against Leishmania major," Science, vol. 263, no. 5144, pp. 235-237, 1994.

[12] L. Soong, J. C. Xu, I. S. Grewal, et al., "Disruption of CD40CD40 ligand interactions results in an enhanced susceptibility to Leishmania amazonensis infection," Immunity, vol. 4, no. 3, pp. 263-273, 1996.

[13] R. D. Stout and J. Suttles, "The many roles of CD40 in cellmediated inflammatory responses," Immunology Today, vol. 17, no. 10, pp. 487-492, 1996.

[14] M. Faris, F. Gaskin, J. T. Parsons, and S. M. Fu, "CD40 signaling pathway: anti-CD40 monoclonal antibody induces rapid dephosphorylation and phosphorylation of tyrosinephosphorylated proteins including protein tyrosine kinase Lyn, Fyn, and Syk and the appearance of a $28-\mathrm{kD}$ tyrosine phosphorylated protein," Journal of Experimental Medicine, vol. 179, no. 6, pp. 1923-1931, 1994.
[15] C. L. Sutherland, A. W. Heath, S. L. Pelech, P. R. Young, and M. R. Gold, "Differential activation of the ERK, JNK, and p38 mitogen-activated protein kinases by CD40 and the B cell antigen receptor," Journal of Immunology, vol. 157, no. 8, pp. 3381-3390, 1996.

[16] M. Kashiwada, Y. Kaneko, H. Yagita, K. Okumura, and T. Takemori, "Activation of mitogen-activated protein kinases via CD40 is distinct from that stimulated by surface $\operatorname{IgM}$ on B cells," European Journal of Immunology, vol. 26, no. 7, pp. 1451-1458, 1996.

[17] B. Su and M. Karin, "Mitogen-activated protein kinase cascades and regulation of gene expression," Current Opinion in Immunology, vol. 8, no. 3, pp. 402-411, 1996.

[18] H. J. Schaeffer and M. J. Weber, "Mitogen-activated protein kinases: specific messages from ubiquitous messengers," Molecular and Cellular Biology, vol. 19, no. 4, pp. 2435-2444, 1999.

[19] J. Han and R. J. Ulevitch, "Emerging targets for antiinflammatory therapy," Nature Cell Biology, vol. 1, no. 2, pp. E39-E40, 1999.

[20] R. J. Davis, "Signal transduction by the JNK group of MAP kinases," Cell, vol. 103, no. 2, pp. 239-252, 2000.

[21] R. Seger and E. G. Krebs, "The MAPK signaling cascade," FASEB Journal, vol. 9, no. 9, pp. 726-735, 1995.

[22] J. H. Her, S. Lakhani, K. Zu, et al., "Dual phosphorylation and autophosphorylation in mitogen-activated protein (MAP) kinase activation," Biochemical Journal, vol. 296, no. 1, pp. 25-31, 1993.

[23] J. Raingeaud, S. Gupta, J. S. Rogers, et al., "Pro-inflammatory cytokines and environmental stress cause p38 mitogenactivated protein kinase activation by dual phosphorylation on tyrosine and threonine," Journal of Biological Chemistry, vol. 270, no. 13, pp. 7420-7426, 1995.

[24] A. Paul, S. Wilson, C. M. Belham, et al., "Stress-activated protein kinases: activation, regulation and function," Cellular Signalling, vol. 9, no. 6, pp. 403-410, 1997.

[25] K. Ono and J. Han, "The p38 signal transduction pathway activation and function," Cellular Signalling, vol. 12, no. 1, pp. 1-13, 2000.

[26] S. J. Ajizian, B. K. English, and E. A. Meals, "Specific inhibitors of p38 and extracellular signal-regulated kinase mitogen-activated protein kinase pathways block inducible nitric oxide synthase and tumor necrosis factor accumulation in murine macrophages stimulated with lipopolysaccharide and interferon- $\gamma$," Journal of Infectious Diseases, vol. 179, no. 4, pp. 939-944, 1999.

[27] R. A. Salmon, X. Guo, H. S. Teh, and J. W. Schrader, “The p38 mitogen-activated protein kinases can have opposing roles in the antigen-dependent or endotoxin-stimulated production of IL-12 and IFN- $\gamma$," European Journal of Immunology, vol. 31, no. 11, pp. 3218-3227, 2001.

[28] T. G. Evans, S. S. Reed, and J. B. Hibbs Jr., "Nitric oxide production in murine leishmaniasis: correlation of progressive infection with increasing systemic synthesis of nitric oxide," American Journal of Tropical Medicine and Hygiene, vol. 54, no. 5, pp. 486-489, 1996.

[29] C. Privé and A. Descoteaux, "Leishmania donovani promastigotes evade the activation of mitogen-activated protein kinases p38, c-Jun N-terminal kinase, and extracellular signal-regulated kinase-1/2 during infection of naive macrophages," European Journal of Immunology, vol. 30, no. 8, pp. 2235-2244, 2000. 
[30] G. J. Feng, H. S. Goodridge, M. M. Harnett, et al., "Extracellular signal-related kinase (ERK) and p38 mitogenactivated protein (MAP) kinases differentially regulate the lipopolysaccharide-mediated induction of inducible nitric oxide synthase and IL-12 in macrophages: Leishmania phosphoglycans subvert macrophage IL-12 production by targeting ERK MAP kinase," Journal of Immunology, vol. 163, no. 12, pp. 6403-6412, 1999.

[31] A. Awasthi, R. Mathur, A. Khan, et al., "CD40 signaling is impaired in L. major-infected macrophages and is rescued by a p38MAPK activator establishing a host-protective memory T cell response," Journal of Experimental Medicine, vol. 197, no. 8, pp. 1037-1043, 2003.

[32] A. D. Foey, M. Feldmann, and F. M. Brennan, "Route of monocyte differentiation determines their cytokine production profile: CD40 ligation induces interleukin 10 expression," Cytokine, vol. 12, no. 10, pp. 1496-1505, 2000.

[33] M. M. Kane and D. M. Mosser, "The role of IL-10 in promoting disease progression in Leishmaniasis," Journal of Immunology, vol. 166, no. 2, pp. 1141-1147, 2001.

[34] R. K. Mathur, A. Awasthi, P. Wadhone, B. Ramanamurthy, and B. Saha, "Reciprocal CD40 signals through p38MAPK and ERK-1/2 induce counteracting immune responses," Nature Medicine, vol. 10, no. 5, pp. 540-544, 2004.

[35] Z. Yang, D. M. Mosser, and X. Zhang, "Activation of the MAPK, ERK, following Leishmania amazonensis infection of macrophages," Journal of Immunology, vol. 178, no. 2, pp. 1077-1085, 2007.

[36] G. Murugaiyan, R. Agrawal, G. C. Mishra, D. Mitra, and B. Saha, "Functional dichotomy in CD40 reciprocally regulates effector T cell functions," Journal of Immunology, vol. 177, no. 10, pp. 6642-6649, 2006.

[37] G. Murugaiyan, R. Agrawal, G. C. Mishra, D. Mitra, and B. Saha, "Differential CD40/CD40L expression results in counteracting antitumor immune responses," Journal of Immunology, vol. 178, no. 4, pp. 2047-2055, 2007.

[38] G. Murugaiyan, S. Martin, and B. Saha, "CD40-induced countercurrent conduits for tumor escape or elimination?" Trends in Immunology, vol. 28, no. 11, pp. 467-473, 2007.

[39] P. M. Boggiatto, F. Jie, M. Ghosh, et al., "Altered dendritic cell phenotype in response to Leishmania amazonensis amastigote infection is mediated by MAP kinase, ERK," American Journal of Pathology, vol. 174, no. 5, pp. 1818-1825, 2009.

[40] A. Rub, R. Dey, M. Jadhav, et al., "Cholesterol depletion associated with Leishmania major infection alters macrophage CD40 signalosome composition and effector function," Nature Immunology, vol. 10, no. 3, pp. 273-280, 2009.

[41] S. Balaraman, V. K. Singh, P. Tewary, and R. Madhubala, "Leishmania lipophosphoglycan activates the transcription factor activating protein 1 in J774A.1 macrophages through the extracellular signal-related kinase (ERK) and p38 mitogen-activated protein kinase," Molecular and Biochemical Parasitology, vol. 139, no. 1, pp. 117-127, 2005.

[42] M. Hallé, M. A. Gomez, M. Stuible, et al., "The Leishmania surface protease GP63 cleaves multiple intracellular proteins and actively participates in p38 mitogen-activated protein kinase inactivation," Journal of Biological Chemistry, vol. 284, no. 11, pp. 6893-6908, 2009.

[43] R. Medzhitov and C. Janeway Jr., "Innate immune recognition: mechanisms and pathways," Immunological Reviews, vol. 173, pp. 89-97, 2000.

[44] R. Medzhitov, "Toll-like receptors and innate immunity," Nature Reviews Immunology, vol. 1, no. 2, pp. 135-145, 2001.
[45] M. G. Netea, C. van der Graaf, J. W. M. Van der Meer, and B. J. Kullberg, "Toll-like receptors and the host defense against microbial pathogens: bringing specificity to the innateimmune system," Journal of Leukocyte Biology, vol. 75, no. 5, pp. 749-755, 2004.

[46] A. Poltorak, X. He, I. Smirnova, et al., "Defective LPS signaling in $\mathrm{C} 3 \mathrm{H} / \mathrm{HeJ}$ and $\mathrm{C} 57 \mathrm{BL} / 10 \mathrm{ScCr}$ mice: mutations in Tlr4 gene," Science, vol. 282, no. 5396, pp. 2085-2088, 1998.

[47] L. Alexopoulou, A. C. Holt, R. Medzhitov, and R. A. Flavell, "Recognition of double-stranded RNA and activation of NF$\kappa \mathrm{B}$ by Toll-like receptor 3," Nature, vol. 413, no. 6857, pp. 732-738, 2001.

[48] R. Medzhitov, P. Preston-Hurlburt, E. Kopp, et al., "MyD88 is an adaptor protein in the hToll/IL-1 receptor family signaling pathways," Molecular Cell, vol. 2, no. 2, pp. 253-258, 1998.

[49] H. Wesche, W. J. Henzel, W. Shillinglaw, S. Li, and Z. Cao, "MyD88: an adapter that recruits IRAK to the IL-1 receptor complex," Immunity, vol. 7, no. 6, pp. 837-847, 1997.

[50] N. Suzuki, S. Suzuki, G. S. Duncan, et al., "Severe impairment of interleukin-1 and Toll-like receptor signalling in mice lacking IRAK-4," Nature, vol. 416, no. 6882, pp. 750-754, 2002.

[51] K. A. Fitzgerald, D. C. Rowe, B. J. Barnes, et al., "LPS-TLR4 signaling to IRF-3/7 and NF- $\kappa \mathrm{B}$ involves the toll adapters TRAM and TRIF," Journal of Experimental Medicine, vol. 198, no. 7, pp. 1043-1055, 2003.

[52] M. Yamamoto, S. Sato, H. Hemmi, et al., "Role of adaptor TRIF in the MyD88-independent toll-like receptor signaling pathway," Science, vol. 301, no. 5633, pp. 640-643, 2003.

[53] D. M. Mosser and A. Brittingham, "Leishmania, macrophages and complement: a tale of subversion and exploitation," Parasitology, vol. 115, supplement, pp. S9-S23, 1997.

[54] I. Becker, N. Salaiza, M. Aguirre, et al., "Leishmania lipophosphoglycan (LPG) activates NK cells through Tolllike receptor-2," Molecular and Biochemical Parasitology, vol. 130, no. 2, pp. 65-74, 2003.

[55] T. R. Hawn, A. Ozinsky, D. M. Underhill, et al., "Leishmania major activates IL- $1 \alpha$ expression in macrophages through a MyD88-dependent pathway," Microbes and Infection, vol. 4, no. 8, pp. 763-771, 2002.

[56] E. Muraille, C. De Trez, M. Brait, et al., "Genetically resistant mice lacking MyD88-adapter protein display a high susceptibility to Leishmania major infection associated with a polarized Th2 response," Journal of Immunology, vol. 170, no. 8, pp. 4237-4241, 2003.

[57] J. F. Flandin, F. Chano, and A. Descoteaux, "RNA interference reveals a role for TLR2 and TLR3 in the recognition of Leishmania donovani promastigotes by interferon- $\gamma$-primed macrophages," European Journal of Immunology, vol. 36, no. 2, pp. 411-420, 2006.

[58] P. Kropf, M. A. Freudenberg, M. Modolell, et al., "Tolllike receptor 4 contributes to efficient control of infection with the protozoan parasite Leishmania major," Infection and Immunity, vol. 72, no. 4, pp. 1920-1928, 2004.

[59] P. Kropf, N. Freudenberg, C. Kalis, et al., "Infection of C57BL/10ScCr and C57BL/10ScNCr mice with Leishmania major reveals a role for Toll-like receptor 4 in the control of parasite replication," Journal of Leukocyte Biology, vol. 76, no. 1, pp. 48-57, 2004.

[60] U. Schleicher, J. Liese, I. Knippertz, et al., "NK cell activation in visceral leishmaniasis requires TLR9, myeloid DCs, and IL-12, but is independent of plasmacytoid DCs," Journal of Experimental Medicine, vol. 204, no. 4, pp. 893-906, 2007. 
[61] J. Liese, U. Schleicher, and C. Bogdan, "TLR9 signaling is essential for the innate NK cell response in murine cutaneous leishmaniasis," European Journal of Immunology, vol. 37, no. 12, pp. 3424-3434, 2007.

[62] D. Chandra and S. Naik, "Leishmania donovani infection down-regulates TLR2-stimulated IL-12p40 and activates IL10 in cells of macrophage/monocytic lineage by modulating MAPK pathways through a contact-dependent mechanism," Clinical and Experimental Immunology, vol. 154, no. 2, pp. 224-234, 2008.

[63] H. W. Murray, H. Masur, and J. S. Keithly, "Cell-mediated immune response in experimental visceral leishmaniasis. I. Correlation between resistance to Leishmania donovani and lymphokine-generating capacity," Journal of Immunology, vol. 129, no. 1, pp. 344-350, 1982.

[64] M. Belosevic, D. S. Finbloom, P. H. Van der Meide, M. V. Slayter, and C. A. Nacy, "Administration of monoclonal anti-IFN- $\gamma$ antibodies in vivo abrogates natural resistance of $\mathrm{C} 3 \mathrm{H} / \mathrm{HeN}$ mice to infection with Leishmania major," Journal of Immunology, vol. 143, no. 1, pp. 266-274, 1989.

[65] K. I. Igarashi, G. Garotta, L. Ozmen, et al., "Interferon- $\gamma$ induces tyrosine phosphorylation of interferon- $\gamma$ receptor and regulated association of protein tyrosine kinases, Jak1 and Jak2, with its receptor," Journal of Biological Chemistry, vol. 269, no. 20, pp. 14333-14336, 1994.

[66] M. Sakatsume, K. I. Igarashi, K. D. Winestock, G. Garotta, A. C. Larner, and D. S. Finbloom, "The Jak kinases differentially associate with the $\alpha$ and $\beta$ (accessory factor) chains of the interferon $\gamma$ receptor to form a functional receptor unit capable of activating STAT transcription factors," Journal of Biological Chemistry, vol. 270, no. 29, pp. 17528-17534, 1995.

[67] U. Boehm, T. Klamp, M. Groot, and J. C. Howard, "Cellular responses to interferon- $\gamma$," Annual Review of Immunology, vol. 15, pp. 749-795, 1997.

[68] G. R. Alvarez, B. S. Zwilling, and W. P. Lafuse, "Mycobacterium avium inhibition of IFN- $\gamma$ signaling in mouse macrophages: toll-like receptor 2 stimulation increases expression of dominant-negative STAT $1 \beta$ by mRNA stabilization," Journal of Immunology, vol. 171, no. 12, pp. 67666773, 2003.

[69] J. T. Harty and M. J. Bevan, "Specific immunity to Listeria monocytogenes in the absence of IFN $\gamma$," Immunity, vol. 3, no. 1, pp. 109-117, 1995.

[70] E. Balish, R. D. Wagner, A. Vázquez-Torres, C. Pierson, and T. Warner, "Candidiasis in interferon- $\gamma^{-/-}$) mice," Journal of Infectious Diseases, vol. 178, no. 2, pp. 478-487, 1998.

[71] V. Amani, A. M. Vigário, E. Belnoue, et al., "Involvement of IFN- $\gamma$ receptor-mediated signaling in pathology and anti-malarial immunity induced by Plasmodium berghei infection," European Journal of Immunology, vol. 30, no. 6, pp. 1646-1655, 2000.

[72] L. E. Rosas, T. Keiser, R. Pyles, J. Durbin, and A. R. Satoskar, "Development of protective immunity against cutaneous leishmaniasis is dependent of STAT1-mediated IFN signaling pathway," European Journal of Immunology, vol. 33, no. 7, pp. 1799-1805, 2003.

[73] D. Nandan and N. E. Reiner, "Attenuation of gamma interferon-induced tyrosine phosphorylation in mononuclear phagocytes infected with Leishmania donovani: selective inhibition of signaling through Janus kinases and Stat1," Infection and Immunity, vol. 63, no. 11, pp. 4495-4500, 1995.

[74] J. Blanchette, N. Racette, R. Faure, K. A. Siminovitch, and M. Olivier, "Leishmania-induced increases in activation of macrophage SHP-1 tyrosine phosphatase are associated with impaired IFN- $\gamma$-triggered JAK2 activation," European Journal of Immunology, vol. 29, no. 11, pp. 3737-3744, 1999.

[75] M. Ray, A. A. Gam, R. A. Boykins, and R. T. Kenney, "Inhibition of interferon- $\gamma$ signaling by Leishmania donovani," Journal of Infectious Diseases, vol. 181, no. 3, pp. 1121-1128, 2000.

[76] P. E. Kima, N. H. Ruddle, and D. McMahon-Pratt, "Presentation via the class I pathway by Leishmania amazonensisinfected macrophages of an endogenous leishmanial antigen to CD8+ T cells," Journal of Immunology, vol. 159, no. 4, pp. 1828-1834, 1997.

[77] S. Hussain, B. S. Zwilling, and W. P. Lafuse, "Mycobacterium avium infection of mouse macrophages inhibits IFN- $\gamma$ Janus kinase-STAT signaling and gene induction by downregulation of the IFN- $\gamma$ receptor," Journal of Immunology, vol. 163, no. 4, pp. 2041-2048, 1999.

[78] R. Fukuda, N. Ishimura, S. Hamamoto, et al., "Co-infection by serologically-silent hepatitis B virus may contribute to poor interferon response in patients with chronic hepatitis $\mathrm{C}$ by down-regulation of type-I interferon receptor gene expression in the liver," Journal of Medical Virology, vol. 63, no. 3, pp. 220-227, 2001.

[79] A. J. Gehring, R. E. Rojas, D. H. Canaday, D. L. Lakey, C. V. Harding, and W. H. Boom, "The Mycobacterium tuberculosis 19-kilodalton lipoprotein inhibits gamma interferonregulated HLA-DR and Fc $\gamma$ R1 on human macrophages through Toll-like receptor 2," Infection and Immunity, vol. 71, no. 8, pp. 4487-4497, 2003.

[80] N. Bhardwaj, L. E. Rosas, W. P. Lafuse, and A. R. Satoskar, "Leishmania inhibits STAT1-mediated IFN- $\gamma$ signaling in macrophages: increased tyrosine phosphorylation of dominant negative STAT $1 \beta$ by Leishmania mexicana," International Journal for Parasitology, vol. 35, no. 1, pp. 75-82, 2005.

[81] L. Xin, K. Li, and L. Soong, "Down-regulation of dendritic cell signaling pathways by Leishmania amazonensis amastigotes," Molecular Immunology, vol. 45, no. 12, pp. 3371-3382, 2008.

[82] K. W. Moore, R. de Waal Malefyt, R. L. Coffman, and A. O'Garra, "Interleukin-10 and the interleukin-10 receptor," Annual Review of Immunology, vol. 19, pp. 683-765, 2001.

[83] G. Grütz, "New insights into the molecular mechanism of interleukin-10-mediated immunosuppression," Journal of Leukocyte Biology, vol. 77, no. 1, pp. 3-15, 2005.

[84] P. Conti, D. Kempuraj, S. Frydas, et al., "IL-10 subfamily members: IL-19, IL-20, IL-22, IL-24 and IL-26," Immunology Letters, vol. 88, no. 3, pp. 171-174, 2003.

[85] M. Vieth, A. Will, K. Schroppel, M. Rollinghoff, and A. Gessner, "Interleukin-10 inhibits antimicrobial activity against Leishmania major in murine macrophages," Scandinavian Journal of Immunology, vol. 40, no. 4, pp. 403-409, 1994.

[86] I. Vouldoukis, P. A. Bécherel, V. Riveros-Moreno, et al., "Interleukin-10 and interleukin-4 inhibit intracellular killing of Leishmania infantum and Leishmania major by human macrophages by decreasing nitric oxide generation," European Journal of Immunology, vol. 27, no. 4, pp. 860-865, 1997.

[87] F. M. Balestieri, A. R. Queiroz, C. Scavone, V. M. Costa, M. Barral-Netto, and A. Abrahamsohn Ide, "Leishmania (L.) amazonensis-induced inhibition of nitric oxide synthesis in host macrophages," Microbes and Infection, vol. 4, no. 1, pp. 23-29, 2002.

[88] K. Taga, H. Mostowski, and G. Tosato, "Human interleukin10 can directly inhibit T-cell growth," Blood, vol. 81, no. 11, pp. 2964-2971, 1993. 
[89] R. Chatelain, S. Mauze, and R. L. Coffman, "Experimental Leishmania major infection in mice: role of IL-10," Parasite Immunology, vol. 21, no. 4, pp. 211-218, 1999.

[90] H. W. Murray, A. L. Moreira, C. M. Lu, et al., "Determinants of response to interleukin-10 receptor blockade immunotherapy in experimental visceral leishmaniasis," Journal of Infectious Diseases, vol. 188, no. 3, pp. 458-464, 2003.

[91] H. W. Murray, C. M. Lu, S. Mauze, et al., "Interleukin-10 (IL10) in experimental visceral leishmaniasis and IL-10 receptor blockade as immunotherapy," Infection and Immunity, vol. 70, no. 11, pp. 6284-6293, 2002.

[92] R. Lang, R. L. Rutschman, D. R. Greaves, and P. J. Murray, "Autocrine deactivation of macrophages in transgenic mice constitutively overexpressing IL-10 under control of the human CD68 promoter," Journal of Immunology, vol. 168, no. 7, pp. 3402-3411, 2002.

[93] S. A. Miles, S. M. Conrad, R. G. Alves, S. M. B. Jeronimo, and D. M. Mosser, "A role for IgG immune complexes during infection with the intracellular pathogen Leishmania," Journal of Experimental Medicine, vol. 201, no. 5, pp. 747754, 2005.

[94] N. Noben-Trauth, R. Lira, H. Nagase, W. E. Paul, and D. L. Sacks, "The relative contribution of IL-4 receptor signaling and IL-10 to susceptibility to Leishmania major," Journal of Immunology, vol. 170, no. 10, pp. 5152-5158, 2003.

[95] S. Nylén and D. Sacks, "Interleukin-10 and the pathogenesis of human visceral leishmaniasis," Trends in Immunology, vol. 28, no. 9, pp. 378-384, 2007.

[96] L. U. Buxbaum and P. Scott, "Interleukin 10- and Fc $\gamma$ receptor-deficient mice resolve Leishmania mexicana lesions," Infection and Immunity, vol. 73, no. 4, pp. 21012108, 2005.

[97] B. N. Thomas and L. U. Buxbaum, "Fc $\gamma$ RIII mediates immunoglobulin G-induced interleukin-10 and is required for chronic Leishmania mexicana lesions," Infection and Immunity, vol. 76, no. 2, pp. 623-631, 2008.

[98] R. P. Donnelly, H. Dickensheets, and D. S. Finbloom, "The interleukin-10 signal transduction pathway and regulation of gene expression in mononuclear phagocytes," Journal of Interferon and Cytokine Research, vol. 19, no. 6, pp. 563-573, 1999.

[99] P. J. Murray, "STAT3-mediated anti-inflammatory signalling," Biochemical Society Transactions, vol. 34, no. 6, pp. 1028-1031, 2006.

[100] E. M. Benkhart, M. Siedlar, A. Wedel, T. Werner, and H. W. L. Ziegler-Heitbrock, "Role of Stat3 in lipopolysaccharideinduced IL-10 gene expression," Journal of Immunology, vol. 165, no. 3, pp. 1612-1617, 2000.

[101] J. K. Riley, K. Takeda, S. Akira, and R. D. Schreiber, "Interleukin-10 receptor signaling through the JAK-STAT pathway. Requirement for two distinct receptor-derived signals for anti-inflammatory action," Journal of Biological Chemistry, vol. 274, no. 23, pp. 16513-16521, 1999.

[102] K. Takeda, B. E. Clausen, T. Kaisho, et al., "Enhanced Th1 activity and development of chronic enterocolitis in mice devoid of Stat3 in macrophages and neutrophils," Immunity, vol. 10, no. 1, pp. 39-49, 1999.

[103] L. Williams, L. Bradley, A. Smith, and B. Foxwell, "Signal transducer and activator of transcription 3 is the dominant mediator of the anti-inflammatory effects of IL-10 in human macrophages," Journal of Immunology, vol. 172, no. 1, pp. 567-576, 2004.
[104] S.-L. Tan and P. J. Parker, "Emerging and diverse roles of protein kinase C in immune cell signalling," Biochemical Journal, vol. 376, no. 3, pp. 545-552, 2003.

[105] M. Olivier, R. W. Brownsey, and N. E. Reiner, "Defective stimulus-response coupling in human monocytes infected with Leishmania donovani is associated with altered activation and translocation of protein kinase C," Proceedings of the National Academy of Sciences of the United States of America, vol. 89, no. 16, pp. 7481-7485, 1992.

[106] A. Descoteaux, G. Matlashewski, and S. J. Turco, "Inhibition of macrophage protein kinase C-mediated protein phosphorylation by Leishmania donovani lipophosphoglycan," Journal of Immunology, vol. 149, no. 9, pp. 3008-3015, 1992.

[107] S. Corradin, J. Mauël, A. Ransijn, C. Stürzinger, and G. Vergères, "Down-regulation of MARCKS-related protein (MRP) in macrophages infected with Leishmania," Journal of Biological Chemistry, vol. 274, no. 24, pp. 16782-16787, 1999.

[108] A. Descoteaux and S. J. Turco, "Glycoconjugates in Leishmania infectivity," Biochimica et Biophysica Acta, vol. 1455, no. 2-3, pp. 341-352, 1999.

[109] Å. Holm, K. Tejle, K.-E. Magnusson, A. Descoteaux, and B. Rasmusson, "Leishmania donovani lipophosphoglycan causes periphagosomal actin accumulation: correlation with impaired translocation of PKC $\alpha$ and defective phagosoem maturation," Cellular Microbiology, vol. 3, no. 7, pp. 439-447, 2001.

[110] Å. Holm, K. Tejle, T. Gunnarsson, K.-E. Magnusson, A. Descoteaux, and B. Rasmusson, "Role of protein kinase C $\alpha$ for uptake of unopsonized prey and phagosomal maturation in macrophages," Biochemical and Biophysical Research Communications, vol. 302, no. 4, pp. 653-658, 2003.

[111] S. Pingel, Z. E. Wang, and R. M. Locksley, "Distribution of protein kinase $\mathrm{C}$ isoforms after infection of macrophages with Leishmania major," Infection and Immunity, vol. 66, no. 4, pp. 1795-1799, 1998.

[112] S. Bhattacharyya, S. Ghosh, P. Sen, S. Roy, and S. Majumdar, "Selective impairment of protein kinase $\mathrm{C}$ isotypes in murine macrophage by Leishmania donovani," Molecular and Cellular Biochemistry, vol. 216, no. 1-2, pp. 47-57, 2001.

[113] S. Bhattacharyya, S. Ghosh, P. L. Jhonson, S. K. Bhattacharya, and S. Majumdar, "Immunomodulatory role of interleukin10 in visceral leishmaniasis: defective activation of protein kinase C-mediated signal transduction events," Infection and Immunity, vol. 69, no. 3, pp. 1499-1507, 2001.

[114] S. Ghosh, S. Bhattacharyya, S. Das, et al., "Generation of ceramide in murine macrophages infected with Leishmania donovani alters macrophage signaling events and aids intracellular parasitic survival," Molecular and Cellular Biochemistry, vol. 223, no. 1-2, pp. 47-60, 2001.

[115] R. Dey, A. Sarkar, N. Majumder, et al., "Regulation of impaired protein kinase $\mathrm{C}$ signaling by chemokines in murine macrophages during visceral leishmaniasis," Infection and Immunity, vol. 73, no. 12, pp. 8334-8344, 2005.

[116] E. E. de Almeida-Amaral, C. Caruso-Neves, L. S. Lara, C. M. Pinheiro, and J. R. Meyer-Fernandes, "Leishmania amazonensis: PKC-like protein kinase modulates the $\left(\mathrm{Na}^{+}+\mathrm{K}^{+}\right)$ATPase activity," Experimental Parasitology, vol. 116, no. 4, pp. 419-426, 2007.

[117] N. Alvarez-Rueda, M. Biron, and P. Le Pape, "Infectivity of Leishmania mexicana is associated with differential expression of protein kinase C-like triggered during a cell-cell contact," PLoS One, vol. 4, no. 10, article e7581, 2009.

[118] A. Ruhland and P. E. Kima, "Activation of PI3K/Akt signaling has a dominant negative effect on IL-12 production by 
macrophages infected with Leishmania amazonensis promastigotes," Experimental Parasitology, vol. 122, no. 1, pp. 28-36, 2009.

[119] T. Fukao, M. Tanabe, Y. Terauchi, et al., "P13K-mediated negative feedback regulation of IL-12 production in DCs," Nature Immunology, vol. 3, no. 9, pp. 875-881, 2002.

[120] A. Yetter, S. Uddin, J. J. Krolewski, H. Jiao, T. Yi, and L. C. Platanias, "Association of the interferon-dependent tyrosine kinase Tyk-2 with the hematopoietic cell phosphatase," Journal of Biological Chemistry, vol. 270, no. 31, pp. 1817918182, 1995.

[121] M. David, H. E. Chen, S. Goelz, A. C. Larner, and B. G. Neel, "Differential regulation of the alpha/beta interferonstimulated Jak/Stat pathway by the $\mathrm{SH} 2$ domain-containing tyrosine phosphatase SHPTP1," Molecular and Cellular Biology, vol. 15, no. 12, pp. 7050-7058, 1995.

[122] P. A. Ram and D. J. Waxman, "Interaction of growth hormone-activated STATs with SH2-containing phosphotyrosine phosphatase SHP-1 and nuclear JAK2 tyrosine kinase," Journal of Biological Chemistry, vol. 272, no. 28, pp. 17694 $17702,1997$.

[123] U. Klingmuller, U. Lorenz, L. C. Cantley, B. G. Neel, and H. F. Lodish, "Specific recruitment of SH-PTP1 to the erythropoietin receptor causes inactivation of JAK2 and termination of proliferative signals," Cell, vol. 80, no. 5, pp. 729-738, 1995.

[124] M. B. Marrero, V. J. Venema, H. Ju, D. C. Eaton, and R. C. Venema, "Regulation of angiotensin II-induced JAK2 tyrosine phosphorylation: roles of SHP-1 and SHP-2," American Journal of Physiology, vol. 275, no. 5, pp. C1216-C1223, 1998.

[125] D. Banville, R. Stocco, and S.-H. Shen, "Human protein tyrosine phosphatase 1C (PTPN6) gene structure: alternate promoter usage and exon skipping generate multiple transcripts," Genomics, vol. 27, no. 1, pp. 165-173, 1995.

[126] J. A. Frearson and D. R. Alexander, "The role of phosphotyrosine phosphatases in haematopoietic cell signal transduction," BioEssays, vol. 19, no. 5, pp. 417-427, 1997.

[127] K. L. Berg, K. Carlberg, L. R. Rohrschneider, K. A. Siminovitch, and E. R. Stanley, "The major SHP-1-binding, tyrosine-phosphorylated protein in macrophages is a member of the KIR/LIR family and an SHP-1 substrate," Oncogene, vol. 17, no. 19, pp. 2535-2541, 1998.

[128] P. A. Ram and D. J. Waxman, "Interaction of growth hormone-activated STATs with SH2-containing phosphotyrosine phosphatase SHP-1 and nuclear JAK2 tyrosine kinase," Journal of Biological Chemistry, vol. 272, no. 28, pp. 17694 17702, 1997.

[129] Y.-G. Yeung, Y. Wang, D. B. Einstein, P. S. W. Lee, and E. R. Stanley, "Colony-stimulating factor-1 stimulates the formation of multimeric cytosolic complexes of signaling proteins and cytoskeletal components in macrophages," Journal of Biological Chemistry, vol. 273, no. 27, pp. 1712817137, 1998.

[130] G. Forget, D. J. Gregory, L. A. Whitcombe, and M. Olivier, "Role of host protein tyrosine phosphatase SHP-1 in Leishmania donovani-induced inhibition of nitric oxide production," Infection and Immunity, vol. 74, no. 11, pp. 6272-6279, 2006.

[131] A. R. Khaled, E. J. Butfiloski, E. S. Sobel, and J. Schiffenbauer, "Functional consequences of the SHP-1 defect in motheaten viable mice: role of NF- $\kappa \mathrm{B}$," Cellular Immunology, vol. 185, no. 1, pp. 49-58, 1998.

[132] P. T. Massa and C. Wu, "Increased inducible activation of NF- $\kappa \mathrm{B}$ and responsive genes in astrocytes deficient in the protein tyrosine phosphatase SHP-1," Journal of Interferon and Cytokine Research, vol. 18, no. 7, pp. 499-507, 1998.

[133] G. Forget, K. A. Siminovitch, S. Brochu, S. Rivest, D. Radzioch, and M. Olivier, "Role of host phosphotyrosine phosphatase SHP-1 in the development of murine leishmaniasis," European Journal of Immunology, vol. 31, no. 11, pp. 3185-3196, 2001.

[134] M. Olivier, B.-J. Romero-Gallo, C. Matte, et al., "Modulation of interferon- $\gamma /$-induced macrophage activation by phosphotyrosine phosphatases inhibition: effect on murine leishmaniasis progression," Journal of Biological Chemistry, vol. 273, no. 22, pp. 13944-13949, 1998.

[135] C. Matte, J.-F. Marquis, J. Blanchette, et al., "Peroxovanadium-mediated protection against murine leishmaniasis: role of the modulation of nitric oxide," European Journal of Immunology, vol. 30, no. 9, pp. 25552564, 2000.

[136] D. Nandan, R. Lo, and N. E. Reiner, "Activation of phosphotyrosine phosphatase activity attenuates mitogen-activated protein kinase signaling and inhibits c-FOS and nitric oxide synthase expression in macrophages infected with Leishmania donovani," Infection and Immunity, vol. 67, no. 8, pp. 4055-4063, 1999.

[137] D. Nandan and N. E. Reiner, "Leishmania donovani engages in regulatory interference by targeting macrophage protein tyrosine phosphatase SHP-1," Clinical Immunology, vol. 114, no. 3, pp. 266-277, 2005.

[138] I. Abu-Dayyeh, M. T. Shio, S. Sato, S. Akira, B. Cousineau, and M. Olivier, "Leishmania-induced IRAK-1 inactivation is mediated by SHP-1 interacting with an evolutionarily conserved KTIM motif," PLoS Neglected Tropical Diseases, vol. 2, no. 12, article e305, 2008.

[139] Y. A. Hannun and L. M. Obeid, "Ceramide: an intracellular signal for apoptosis," Trends in Biochemical Sciences, vol. 20, no. 2, pp. 73-77, 1995.

[140] Y. A. Hannun, "Functions of ceramide in coordinating cellular responses to stress," Science, vol. 274, no. 5294, pp. 1855-1859, 1996.

[141] S. Mathias, L. A. Peña, and R. N. Kolesnick, "Signal transduction of stress via ceramide," Biochemical Journal, vol. 335, no. 3, pp. 465-480, 1998.

[142] J. D. Saba, L. M. Obeid, and Y. A. Hannun, "Ceramide: an intracellular mediator of apopotosis and growth supression," Philosophical Transactions of the Royal Society B, vol. 351, no. 1336, pp. 233-241, 1996.

[143] R. Dey, N. Majumder, S. Bhattacharjee, et al., "Leishmania donovani-induced ceramide as the key mediator of Akt dephosphorylation in murine macrophages: role of protein kinase $\mathrm{C} \zeta$ and phosphatase," Infection and Immunity, vol. 75, no. 5, pp. 2136-2142, 2007.

[144] S. Kuroda, M. Nishio, T. Sasaki, et al., "Effective clearance of intracellular Leishmania major in vivo requires Pten in macrophages," European Journal of Immunology, vol. 38, no. 5, pp. 1331-1340, 2008. 

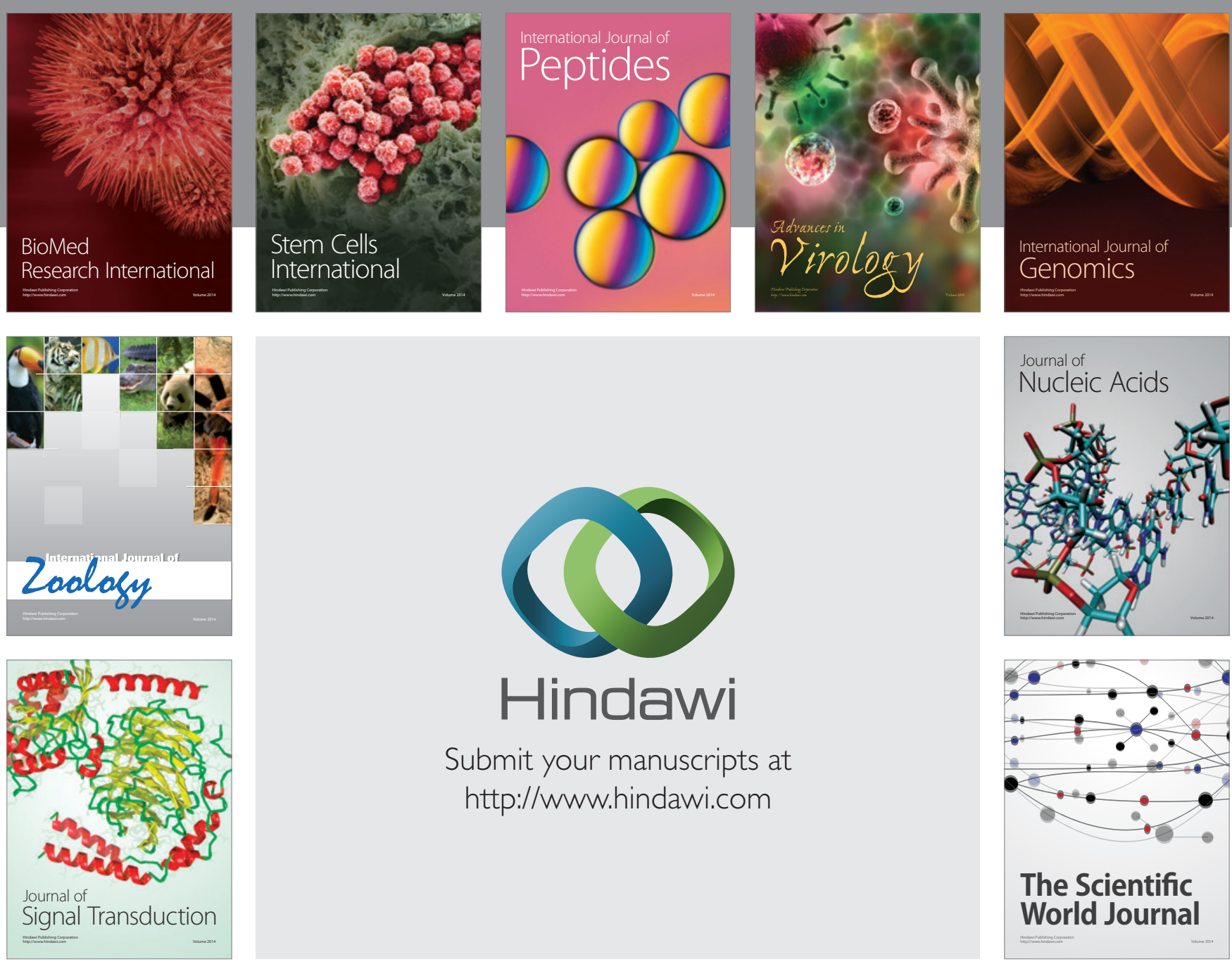

Submit your manuscripts at

http://www.hindawi.com
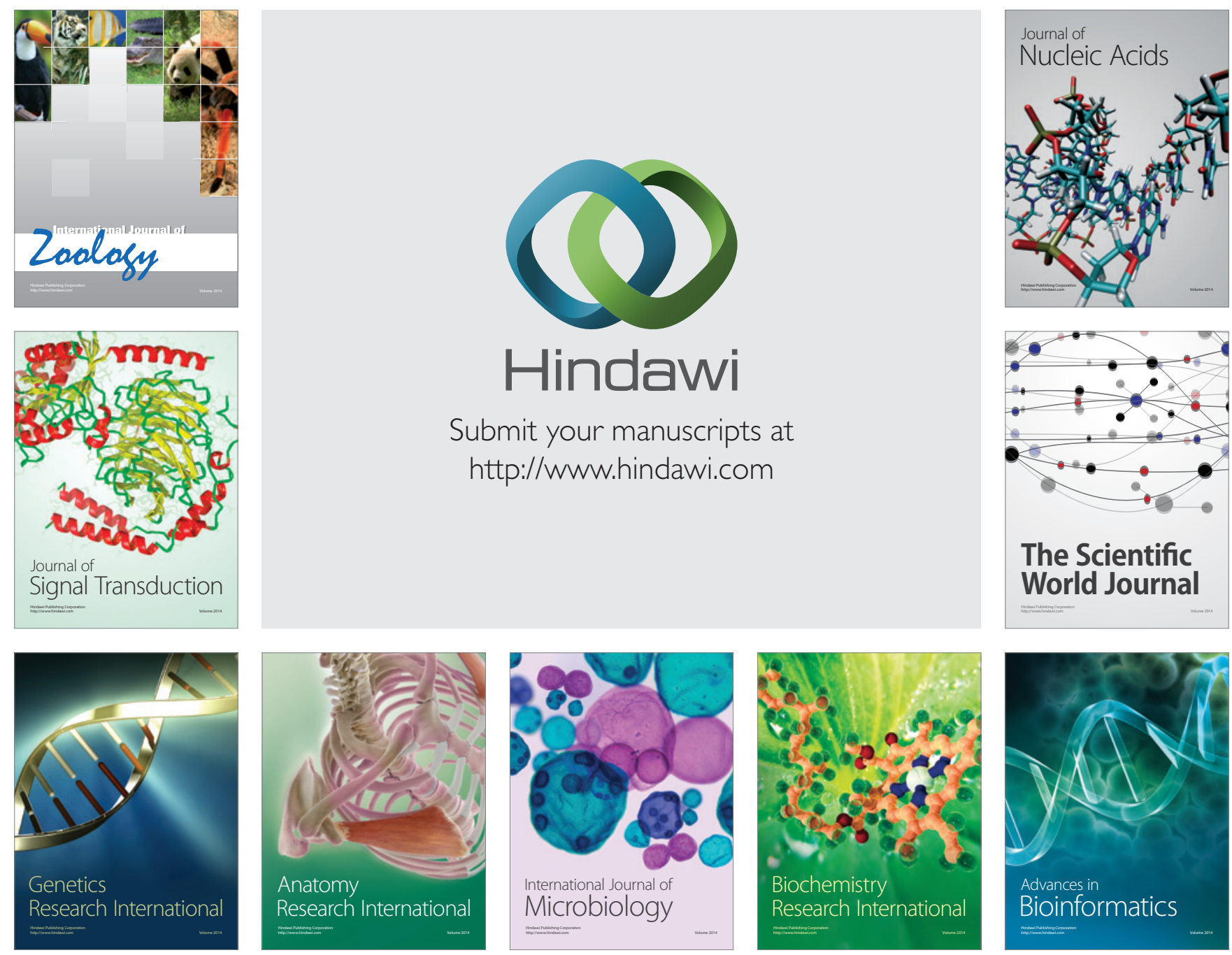

The Scientific World Journal
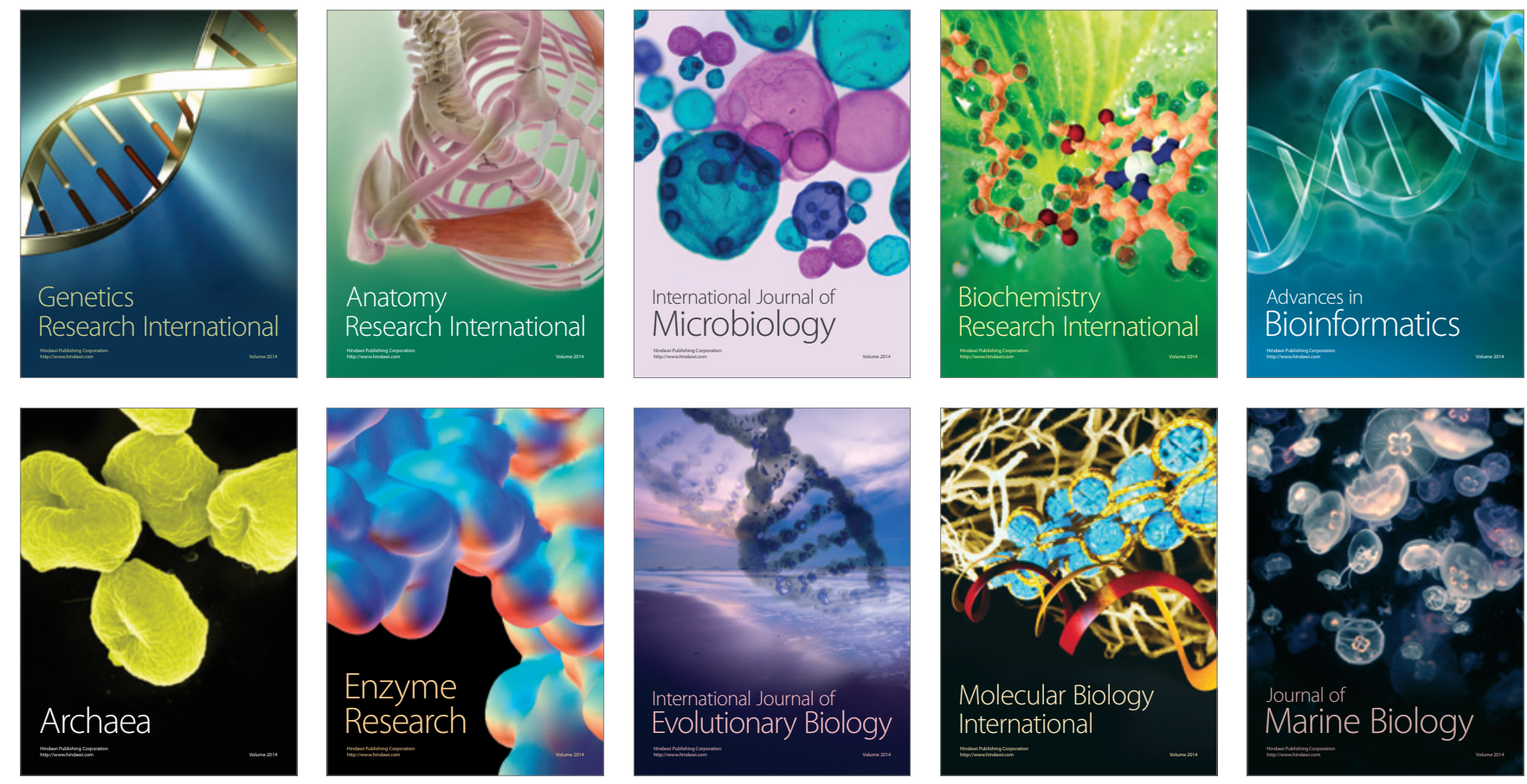